\title{
Interrelationship between Angiotensin and Catecholamines
}

\author{
Tatsuo Sato, M.D., Masaru Maebashi, M.D., Koji Goto, M.D., and \\ Kaoru Yoshinaga, M.D.
}

\section{SUMMARY}

Urinary catecholamines were measured with an attempt for making differential diagnosis of various types of hypertension in which reninangiotensin system is or is not operating. This was based on recent evidences that angiotensin is a potent releaser of catecholamines and aldosterone from the adrenal glands. Twenty patients with essential hypertension, 5 malignant hypertension, 5 renovascular hypertension and 5 primary aldosteronism were subjected to the study. However, no changes in urinary catecholamine excretion were found and all values remained in normal range.

Hypertensive doses of angiotensin infusion to normal men did not alter the output of adrenaline in urine, but did produce a marked decrease in noradrenaline excretion. In rats, intraperitoneal injection of angiotensin induced significant increase in noradrenaline content in the heart, while catecholamine levels in the adrenal glands were remained unchanged after angiotensin administration. Additional experiment showed that infusion of angiotensin to dogs enhanced the blood pressure response to tyramine.

The data indicated that differential diagnosis of hypertension due to primary and secondary aldosteronism was impossible by means of urinary catecholamine assay. With the data obtained from angiotensin treatment in man and in animal, though it was indirect evidence, the authors concluded that there may be an inhibitory mechanism of the sympathetic nervous system in order to adapt to hypertensive state which is produced by angiotensin.

\section{Additional Indexing Words :}

Angiotensin Catecholamine Hypertension Primary or secondary aldosteronism Tyramine Sympathetic nervous system

TN 1964, Feldberg and Lewis ${ }^{1)}$ reported that angiotensin can release catecholamines from the adrenal glands, and suggested that the vasoconstrict-

From the Department of Internal Medicine, Tohoku University School of Medicine, Sendai. Presented in part at the 40th Annual Meeting of the Japan Endocrinological Society in Nagoya, April 5, 1967

Received for publication June 19, 1967. 
ing action of angiotensin may be related to the secretion of catecholamines from the sympathetic nerve endings in the vessel wall." Since then, many reports have been published with or without confirmation of their suggestions. ${ }^{3-8)}$ In addition, it has been well known that angiotensin is a potent releaser of aldosterone from the adrenal cortex.

These considerations prompted us to study an interrelationship between angiotensin and catecholamines. If the hypothesis of Feldberg and Lewis ${ }^{1,2)}$ is acceptable, it is presumably expected that different excretion pattern of urinary catccholamines may be found in patients with malignant hypertension or with renovascular hypertension in whom renin-angiotensin-aldosterone system is considered to be accelerated, and in patients with primary aldosteronism in whom renin-angiotensin system is suppressed. In spite of recent knowledges in pathologic physiology of primary aldosteronism, establishment of its diagnosis is still difficult, particularly in normokalemic state, because of requirement of specialized technics or equipments for assay of aldosterone and renin. Thus, if measurement of catecholamines gives some informations in differential diagnosis of these types of hypertension, it could be a great aid in clinical practice.

In the present paper, the authors wish to report the estimated values of urinary catecholamines in these various types of hypertension and additional experimental data obtained in human and animal studies, and to discuss the interrelationship between angiotensin and catecholamines.

\section{Methods}

Twenty-four-hour urine samples were collected in a bottle containing $10 \mathrm{ml}$. of concentrated hydrochloric acid. Free catecholamines in urine were measured in 20 patients with essential hypertension, 5 patients with malignant hypertension, 5 patients with renovascular hypertension and 5 patients with primary aldosteronism. The diagnosis of these patients except essential hypertension was verified at the time of surgery or autopsy. Fifty $\mathrm{ml}$. aliquot of urine was stirred with $1.0 \mathrm{Gm}$. of activated alumina at $\mathrm{pH} 8.4$, and poured into a column. After washing with water, the adsorbed catecholamines were eluted with $10 \mathrm{ml}$. of $0.2 \mathrm{~N}$ acetic acid. Adrenaline and noradrenaline were analyzed by trihydroxyindole method of Euler and Floding. ${ }^{\text {") }}$

Angiotensin infusion was carried out in 4 normal male adults to know the effect on urinary catecholamine output. The subjects were in fasting state and were remained in the supine position throughout the study except the time of urine collection. After emptying their bladder, the subjects were in bed quietly for 1 hour prior to the infusion and blood pressure was recorded at each $5 \mathrm{~min}$. interval. One hour urine was then collected in a bottle containing $5 \mathrm{ml}$. of $2 \mathrm{~N} \mathrm{HCl}$ and served as control specimen. Angiotensin infusion was started in doses to elevate and keep systolic blood pressure by approximately $30 \mathrm{~mm} . \mathrm{Hg}$, usually about 
$0.02 \mu \mathrm{g} . / \mathrm{Kg} . / \mathrm{min}$., and continued for 1 hour. Urine was collected again and was subjected to assay of catecholamines. In 2 of 4 subjects, effect of sub-hypertensive doses of angiotensin, about $0.006 \mu \mathrm{g} . / \mathrm{Kg} . / \mathrm{min}$., on the excretion pattern of catecholamines in urine was studied simultaneously.

In order to know the effect of angiotensin on tissue catecholamine level, $0.4 \mathrm{ng}$. $/ \mathrm{Gm}$. of angiotensin was injected intraperitoneally to white male rats weighing 120 to $130 \mathrm{Gm}$. and the animals were sacrificed at 2 and $10 \mathrm{~min}$. after injection by a blow on the head. The heart and adrenal glands were removed immediately, weighed and homogenized with 10 per cent of trichloroacetic acid. After centrifugation at 10,000 r.p.m. for 20 min., clear supernatant was subjected to assay of catecholamines according to the method of Euler et al. ${ }^{9)}$

Blood pressure response to tyramine before and after infusion of angiotensin was studied in 2 male dogs weighing about $12 \mathrm{Kg}$. Under pentobarbital anesthesia, $40 \mathrm{mg}$. per $\mathrm{Kg}$. intravenously, carotid blood pressure was measured continuously with a strain gauge transducer and recorded on a direct pen-writing oscillograph. When blood pressure had stabilized, 0.3 and $0.5 \mathrm{mg}$. of tyramine hydrochloride were injected through the end of polyethylene tube inserted into the femoral vein. Then angiotensin infusion, $1 \mu \mathrm{g}$. of angiotensin per ml. of 5 per cent glucose, was started and systolic blood pressure was kept in an elevation of $20 \mathrm{~mm} . \mathrm{Hg}$ above the base line. An equal amount of tyramine was injected again and blood pressure response was compared with that of pre-infusion.

\section{Results}

1) Urinary excretion of catecholamines in various types of hypertension: There were no significant differences in adrenaline and noradrenaline excretion in urine between patients with malignant or renovascular hypertension and with primary aldosteronism. As shown in Fig. 1, all values estimated were remained in normal range (in our laboratory it was 0 to $10 \mu \mathrm{g}$./day for adrenaline and 10 to $50 \mu \mathrm{g}$./day for noradrenaline). In addition, it was difficult to find any difference in catecholamine concentrations in urine from patients with essential hypertension and with secondary hypertension.

\begin{tabular}{|c|c|c|}
\hline & \multicolumn{2}{|c|}{ Catecholamine Excretion ( $\mu \mathrm{g} /$ day) } \\
\hline & $\begin{array}{l}\text { Adrenaline } \\
0 \\
0\end{array}$ & $10 \quad 20 \quad 30 \quad 40$ \\
\hline Essential Hypertension & 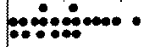 & .m. . . . \\
\hline Malignant Hypertension & $\cdots \cdots$ & $\bullet \bullet$ \\
\hline Renovasculer Hypertension & $\cdots \cdots$ & $\bullet \bullet \bullet$ \\
\hline Primary Aldosterenism & م- & $\bullet \bullet$ \\
\hline Normal Range & $0-10$ & $10-50$ \\
\hline
\end{tabular}

Fig. 1. Urinary excretion of adrenaline and noradrenaline in patients with various types of hypertension. 
2) Effect of infused angiotensin on urinary catecholamines in normal subjects: Table I presents the data in this study. Forty to sixty per cent decrease

Table I. Changes in Urinary Excretion Pattern of Catecholamines Before and After Angiotensin Infusion in Man

\begin{tabular}{|c|c|c|c|c|c|c|c|c|c|c|c|c|}
\hline \multirow{3}{*}{ Subjects } & \multirow{3}{*}{ Age } & \multirow{3}{*}{$\operatorname{Sex}$} & \multicolumn{10}{|c|}{ Urinary Catecholamines* } \\
\hline & & & \multirow{2}{*}{\multicolumn{2}{|c|}{ Pre-infusion }} & \multicolumn{8}{|c|}{ Post-infusion } \\
\hline & & & & & \multicolumn{4}{|c|}{$\begin{array}{c}\text { Sub-hypertensive Doses } \\
\text { Infusion }\end{array}$} & \multicolumn{4}{|c|}{$\begin{array}{l}\text { Hypertensive Doses } \\
\text { Infusion }\end{array}$} \\
\hline 1) T.S. & 38 & $\mathbf{M}$ & A & $\begin{array}{l}0.07 \\
0.69\end{array}$ & $(0.007)$ & $\stackrel{\mathrm{A}}{\mathrm{NA}}$ & $\begin{array}{l}0.08 \\
0.73\end{array}$ & $\begin{array}{l}+14 \\
+\quad 4\end{array}$ & $(0.026)$ & A & $\begin{array}{l}0.07 \\
0.28\end{array}$ & $\begin{array}{r}0 \\
-60\end{array}$ \\
\hline 2) K. G. & 35 & $\mathrm{M}$ & $\begin{array}{l}\mathrm{A} \\
\mathrm{NA}\end{array}$ & $\begin{array}{l}0.15 \\
0.50\end{array}$ & $(0.0056)$ & $\begin{array}{l}\text { A } \\
\text { NA }\end{array}$ & $\begin{array}{l}0.15 \\
0.45\end{array}$ & $\begin{array}{r}0 \\
-10\end{array}$ & $(0.020)$ & A & $\begin{array}{l}0.14 \\
0.30\end{array}$ & $\begin{array}{l}-7 \\
-40\end{array}$ \\
\hline 3) $\mathrm{M} . \mathrm{M}$. & 34 & $\mathbf{M}$ & $\begin{array}{l}\text { A } \\
\text { NA }\end{array}$ & $\begin{array}{l}0.29 \\
0.55\end{array}$ & & & & & $(0.025)$ & $\begin{array}{l}\text { A } \\
\text { NA }\end{array}$ & $\begin{array}{l}0.30 \\
0.20\end{array}$ & $\begin{array}{l}+3 \\
-64\end{array}$ \\
\hline 4) O.A. & 35 & $\mathbf{M}$ & $\begin{array}{l}\text { A } \\
\text { NA }\end{array}$ & $\begin{array}{l}0.11 \\
0.36\end{array}$ & & & & & $(0.023)$ & $\begin{array}{l}\text { A } \\
\text { NA }\end{array}$ & $\begin{array}{l}0.10 \\
0.18\end{array}$ & $\begin{array}{r}-9 \\
-50\end{array}$ \\
\hline
\end{tabular}

* $\mu \mathrm{g}$./hour ** $\mu \mathrm{g}$. $/ \mathrm{Kg}$. $/ \mathrm{min}$.

A : adrenaline NA : noradrenaline
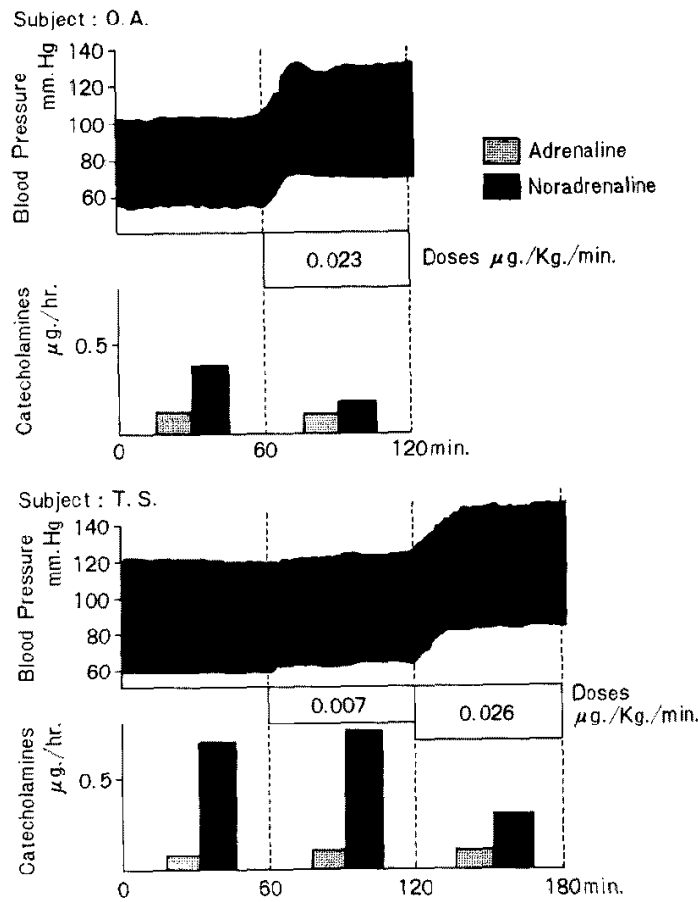

Fig. 2. Urinary excretion of catecholamines before and after angioten$\sin$ infusion in man. 
in noradrenaline excretion was observed in all subjected when angiotensin was infused in hypertensive doses, while adrenaline excretion remained unchanged. On the other hand, sub-hypertensive doses of angiotensin did not alter the excretion pattern of urinary catecholamines. Fig. 2 shows a typical course of the experiment. Angiotensin produced negligible changes in heart rate during the infusion.

3) Effect of angiotensin on tissue catecholamine level: Preliminary study showed that single intraperitoneal injection of $0.4 \mathrm{ng}$. of angiotensin per $\mathrm{Gm}$. of body weight in rats produced more than $20 \mathrm{~mm} . \mathrm{Hg}$ elevation of mean arterial blood pressure. The blood pressure changes returned to pre-injection level in $4 \mathrm{~min}$. In the present study, the animals were killed at 2 and $10 \mathrm{~min}$. after angiotensin injection. In Table II, it can be seen that in the heart angiotensin produced significant increase in noradrenaline content at $2 \mathrm{~min}$. after the injection. This was followed by slight decrease at $10 \mathrm{~min}$. There were no significant changes in adrenal catecholamine levels between control and angiotensin-treated rats.

4) Blood pressure response to tyramine before and after angiotensin infusion to dogs: Fig. 3 illustrates a record in this experiment. Marked augmentation in blood pressure response to tyramine was found in all 2 dogs after angio-

Table II. Effect of Angiotensin on Tissue Catecholamine Levels in Rat

\begin{tabular}{|c|c|c|c|c|}
\hline \multirow{3}{*}{ Organs } & \multicolumn{4}{|c|}{ Tissue Catecholamines Content* } \\
\hline & \multirow{2}{*}{\multicolumn{2}{|c|}{ Control $(\mathrm{N}=9)$}} & \multicolumn{2}{|c|}{ After Angiotensin Injection** } \\
\hline & & & 2 min. $(N=10)$ & 10 min. $(N=9)$ \\
\hline Heart & Noradrenaline & $0.50 \pm 0.08$ & $0.68 \pm 0.02$ & $0.59 \pm 0.02$ \\
\hline Adrenal & Adrenaline & $650 \pm 115$ & $610 \pm 86$ & $704 \pm 185$ \\
\hline Glands & Noradrenaline & $187 \pm 77$ & $221 \pm 59$ & $178 \pm 74$ \\
\hline
\end{tabular}

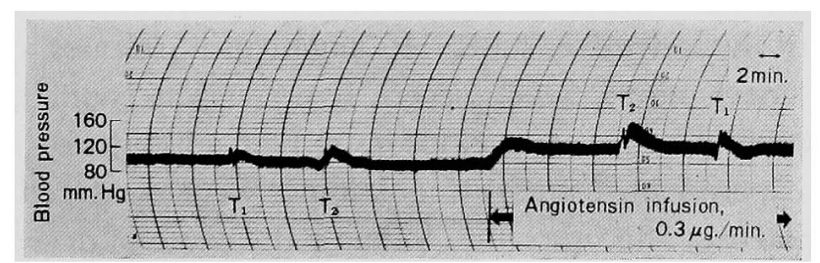

Fig. 3. Blood pressure response to tyramine before and after angioten$\sin$ infusion in dog.

Dog: $11.5 \mathrm{Kg}$., female

$T_{1}$ : Tyramine hydrochloride, $0.3 \mathrm{mg}$.

$\mathrm{T}_{2}$ : , , , $0.5 \mathrm{mg}$. 
tensin infusion. Responsiveness to tyramine increased 1.7 times in an average during hypertensive state produced by angiotensin as compared with that of control period.

\section{DisGussion}

If angiotensin is a potent liberator of catecholamines as mentioned by Feldberg et al., ${ }^{1,2)}$ it could be expected an increased excretion of catecholamines in urine from patients with hypertension due to secondary hyperaldosteronism, malignant hypertension and renovascular hypertension. Contrariwise, a reduced excretion of catecholamines may be observed in patients with primary aldosteronism. However, it was difficult to find any difference in urinary catecholamines excretion between primary and secondary hyperaldosteronism. Some possibilities may arise that actual changes of catecholamines in the body are obscured on account of the present assay method or experimental condition, since they reflect a summation of events occurring for 24 hours. In any way, our attempt for making differential diagnosis of these types of hypertension failed.

To evaluate the hypothesis of Feldberg et al. ${ }^{1,2)}$ the effect of angiotension on excretion pattern of catecholamines in urine, particularly of adrenaline, was examined in normal subjects. As mentioned above, a significant decrease in noradrenaline excretion was found in all subjects after hypertensive doses of angiotensin infusion, while adrenaline was unchanged. Sub-hypertensive doses of angiotensin did not produce any changes in adrenaline and noradrenaline excretion. According to recent concept of catecholamine investigation, circulating amines are taken up, stored and bound in tissue which serve as an important mechanism for inactivating this hormone. ${ }^{10}$ It may be possible to explain that the decrease in noradrenaline excretion after angiotensin probably due to an acceleration of uptake mechanism of noradrenaline in the body. Another explanation is that there may be an inhibition in a spontaneous release of noradrenaline from the sympathetic nerve ending to protect against hypertensive state. If angiotensin releases catecholamines without such mechanisms, much severe hypertension could be induced by cumulative action of both potent vasoconstricting substances.

In next experiment, tissue catecholamines were measured in rats before and after angiotensin administration to know the cause of decreased excretion of noradrenaline in urine. Significant increase in cardiac noradrenaline contents was found after angiotensin treatment, while adrenal catecholamine contents remained unchanged. The data gave no definite indication that angiotensin releases catecholamines so far as tested by the present assay 
method, but gave some indirect evidences that, when hypertension developed by angiotensin, tissue catecholamines level increased presumably due to an accelerated uptake mechanism or inhibited noradrenaline release from the tissue. Significant decrease in noradrenaline excretion was then occurred. Although the present experiment did not show the source of increased catecholamines in the heart, two possible origins may exist. One of them is catecholamines released from adrenal glands or the sympathetic nerve endings, and the other is that of originally existed in the heart. Since adrenal catecholamines levels remained unchanged after angiotensin, it seemes likely that increased catecholamines in the heart may possibly be a result of inhibition of release of noradrenaline.

Tyramine, which is known to act by releasing noradrenaline from the tissue, ${ }^{11)}$ was injected to dogs before and after angiotensin infusion. Apparent augmentation of the blood pressure response to tyramine was observed after angiotensin infusion. This phenomenon may accounted for that tissue catecholamines were accumulated in the body during hypertension induced by angiotensin. Similar results have been reported by $\mathrm{McCubbin}$ et al. ${ }^{12}$ ) in dog. Kaneko et al. ${ }^{13)}$ reported that enhanced blood pressure response to tyramine after angiotensin was observed in man. Interesting is that they ${ }^{11}$ also found greater responses to tyramine in patients with renovascular hypertension as compared to those in normotensives and in patients with essential hypertension.

From these data, the authors concluded that there may be an inhibitory mechanism of the sympathetic nervous system to protect against hypertensive state which is produced by angiotensin.

\section{REFERENCES}

1. Feldberg, W., et al. : J. Physiol. 171: 98, 1964.

2. Feldberg, W, et al. : J. Physiol. 178: 239.1965.

3. Peach, M. J., et al. : Circulat. Res. $19: 571,1966$.

4. Ross, G., et al. : Am. J. Physiol. 211 : 1419, 1966.

5. Robinson, R. L. : Fed. Proc. 24 : 404, 1965.

6. Buckley, J. P. : Acta Physiol. Scand. 65 : 273, 1965.

7. Sakurai, T. : Jap. J. Urolog. Soci. 56 : 1035, 1965.

8. Westfall, T. C., et al. : Biochem. Pharmacol. 14: 1916, 1965.

9. Euler, U. S., et al. : Acta Physiol. Scand. 33 (Suppl. 118) : 57, 195".

10. Axelrod, J.: Progr. Hormone Res. 21 : 597, 1965.

11. Burn, J. H., et al. : J. Physiol. $144: 314,1958$.

12. McCubbin, W., et al. : Circulat. Res. 12 : 553, 1963.

13. Kaneko, Y., et al. : Circulat. Res. $19: 673,1966$. 